\title{
Improvement in Diagnosis and Treat-to-Target Management of Hyperuricemia in Gout: Results from the GEMA-2 Transversal Study on Practice
}

\author{
Fernando Perez Ruiz (D) Carlos A. Sanchez-Piedra · Jesus T. Sanchez-Costa • Mariano Andrés • \\ Cesar Diaz-Torne · Mercedes Jimenez-Palop • Eugenio De Miguel • Carmen Moragues • \\ Francisca Sivera
}

Received: October 31, 2017 / Published online: December 4, 2017

(C) The Author(s) 2017. This article is an open access publication

\section{ABSTRACT}

Introduction: The objective of the study was to evaluate changes regarding main European League Against Rheumatism (EULAR) recommendations on diagnosis and treatment of gout compared to a previous assessment.

Methods: The GEMA-2 (Gout Evaluation and MAnagement) is a transversal assessment of practice for gout by rheumatologists. Main outcome variables were improvement of the previous GEMA assessment regarding the rate of crystal-proven diagnosis and that reaching therapeutic serum urate target below $6 \mathrm{mg} / \mathrm{dl}$ at

Enhanced content To view enhanced content for this article go to www.medengine.com/Redeem/F8FCF0604 111EB7E.

F. Perez Ruiz

Hospital Universitario Cruces e Instituto de Investigación Biomédica Biocruces, Vizcaya, Spain

F. Perez Ruiz ( $\square)$

Universidad del País Vasco, Vizcaya, Spain

e-mail: fperezruiz@telefonica.net

C. A. Sanchez-Piedra · J. T. Sanchez-Costa Unidad de Investigación, Sociedad Española de Reumatología, Madrid, Spain

M. Andrés

Hospital General Universitario de Alicante, Alicante, Spain

M. Andrés

Universidad Miguel Hernández, Alicante, Spain last visit. Other management variables (prophylaxis, treatment of flares, lifestyle change advice) were also evaluated along with general characteristics. The sample was powered to include at least 483 patients for up to $50 \%$ change.

Results: Data on management of 506 patients were retrieved from 38 out of 41 rheumatology units that participated in the previous GEMA audit. Crystal-proved diagnosis rate increased from $26 \%$ to $32 \%$ (31\% improvement) and was higher in gout-dedicated practices; ultrasonography contributed to diagnosis in less than $1 \%$ of cases. Therapeutic serum urate at last visit improved from $41 \%$ to $64 \%$ of all patients (66\% of patients on urate-lowering medications), in any case over $50 \%$ improvement from the

C. Diaz-Torne

Hospital de la Santa Cruz y San Pablo, Barcelona, Spain

M. Jimenez-Palop

Hospital Universitario Puerta de Hierro, Madrid, Spain

E. De Miguel

Hospital Universitario La Paz, Madrid, Spain

C. Moragues

Hospital Universitario Bellvitge, Barcelona, Spain

F. Sivera

Hospital Universitario de Elda, Alicante, Spain 
previous assessment. The use of any urate-lowering medication available was not prescribed as per label dosing in patients who failed to achieve target serum urate. Clinical inertia to increase doses of either allopurinol or febuxostat was still present in clinical practice.

Conclusion: Over 50\% improvement in targeting therapeutic serum urate has been observed, but clinical inertia is still present. Diagnosis is still mostly clinically based, ultrasonography not being commonly contributive.

Funding: Menarini España.

Keywords: Audit; Diagnosis; Gout management; Treatment

\section{INTRODUCTION}

Gout is commonly regarded as a poorly managed disease [1]. Recommendations for diagnosis and management are based on the best evidence and expertise available to obtain the best possible outcomes. Adherence to recommendations, such as prescription rates of uratelowering medications, is reportedly low in general practice [2], even worsening over time in terms of controlling serum urate (sUA) levels [3]. It remains unknown whether such recommendations have a true impact on gout. Whereas an audit of a single outpatient clinic practice demonstrated good adherence to guidelines [4], this does not reflect global practice or an improvement upon previous standards.

The GEMA (Gout Evaluation and MAnagement) study assessed rheumatology practice in Spain in comparison to the European League Against Rheumatism (EULAR) 2006 recommendations for gout and found that, even in a theoretical gold-standard setting, optimal diagnosis was achieved only in approximately one in four patients and target sUA in less than one in two [5]. The GEMA-2 study was conceived and developed as a commitment, within the design of GEMA, to evaluate changes in rheumatology practice over time.

\section{METHODS}

The GEMA-2 study, which is cross-sectional in design, relies on medical records as its primary data source. Centers previously involved in the GEMA study were asked to undergo an additional audit to assess any changes in their adherence to the 2006 EULAR recommendations $[6,7] 5$ years after the initial GEMA study assessment and before the 2012 recommendations would have had an impact on clinical practice [8].

The study was carried out in accordance with the Declaration of Helsinki, was approved by a central institutional review board (IRB), and was agreed upon by the pertinent boards at each center. This study was funded by the Spanish Rheumatology Foundation through an unrestricted grant from Menarini España, which had no access or influence on data capture, analysis, or interpretation of results.

\section{Study Population and Outcomes}

The population sample was calculated to include at least 483 patient files to be able to evaluate changes over 50\% from GEMA to GEMA-2 in both crystal-based diagnosis and the achievement of the targeted sUA level below $6 \mathrm{mg} / \mathrm{dl}(0.36 \mathrm{mmol} / \mathrm{l})$. The cases were randomly selected using the same methodology as in GEMA, as previously described [5]. All 41 centers that participated in GEMA were invited to participate in GEMA-2. To be included, cases had to meet the following criteria: (1) diagnosis of gout as determined by a specialist in rheumatology; (2) a first visit to a rheumatology unit between 1 January 2008 and 31 December 2012; (3) at least one follow-up evaluation at the rheumatology unit during 2013, the last visit being used as an index reference. The time period restriction for inclusion was to avoid any impact from the dissemination of the 2012 American College of Rheumatology guidelines [8] as well as the 2013 national guidelines [9]. 


\section{Data Collection and Variables}

The registry was compiled between October 2014 and May 2015 using a centralized electronic case report form (CRF). Specific guidelines including codes and definitions were created and provided to all GEMA-2 investigators in order to standardize and clarify data collection. Data quality was assessed via onlinemonitored control to detect and clarify all inconsistencies, missing values, and discrepancies. A random sample of patients was monitored on-site at nine participating centers, all randomly selected.

Study variables included in the CRF, identical to those evaluated in GEMA, encompassed demographic and lifestyle data, associated comorbidities, diagnosis of gout, and evaluation of disease burden, clinical characteristics, and treatments for gout (medications for flares, prophylaxis, and urate-lowering drugs) prescribed both prior to and ongoing at the last visit [5]. Additional variables characterizing each unit were obtained from the local principal investigator or head of unit as applicable; specifically, the availability of a specific gout-dedicated clinic, a polarizing microscope, an ultrasonography machine, a specific protocol for gout, implementation of EULAR recommendations at any time since their publication, and a perception of achieving gold standard diagnoses and sUA targets in at least $50 \%$ of patients.

\section{Statistical Analysis}

Means and standard deviations for numeric variables based on normal distribution, as well as absolute and relative frequencies for categorical variables, were calculated. A sensitivity analysis based on the presence or absence of data in the medical charts was also carried out. Comparisons between groups were tested with the statistic appropriate to the distribution of the variables investigated and the number of groups (Chi-squared, Mann-Whitney's $U$, or Student's $t$ ). All analyses were performed using SPSS 21.0 for Windows (SPSS Inc., Chicago, Illinois, USA). Statistical significance was established at $p<0.05$.

\section{RESULTS}

\section{General Data}

Data from 506 patients, from 38 out of 41 rheumatology units, was obtained. The specific rheumatology unit questionnaire was fulfilled by 31 out of 38 units ( $81.6 \%$ ); of these, 28 $(90.3 \%)$ had an on-site microscopy facility, although on-site searches for crystals were performed in only 24 of them (77.4\%). Twentynine rheumatology units $(93.5 \%)$ had such equipment in their offices. Two units (6.5\%) confirmed that a gout-specific clinic facility was available, and $10(32.2 \%)$ indicated that a specific protocol for gout management was present at their offices. The EULAR 2006 recommendations had been discussed at least once in $22(70.9 \%)$ of the rheumatology units, and in $6(19.4 \%)$ more than once.

The general characteristics of the patients are shown in Table 1. It is worth noting that in these patients, the time from diagnosis was close to 7 years, and time from diagnosis to rheumatology evaluation was 3 years. Tophi were recorded in 168/499 $(33.7 \%)$ of patients: $125(53.5 \%)$ at multiple locations. In addition, $427 / 506$ (84.4\%) suffered a flare in the year prior to their first visit, and 283 (55.9\%) suffered two or more flares during that year.

\section{Diagnosis}

Thirty-one out of 38 rheumatology units responded to the pre-study questionnaire with $15(39.5-48.4 \%)$ having predicted that over 50\% of their patients had a diagnosis based on crystal identification. However, crystal-proven diagnosis was obtained in only $162 / 506(32.0 \%)$ patients. As the rate of crystal-proven diagnosis attained in the GEMA audit was 26.0\% (209/ 803) [5], the improvement in crystal-proven diagnosis was just $31 \%$. For patients with noncrystal-proved diagnosis, it was based on just clinical findings in 35 patients (6.9\%), on clinical findings plus hyperuricemia in 273 (54.0\%), on clinical plus radiographic findings in 32 $(6.3 \%)$, and on specific ultrasonographic 
Table 1 General patient characteristics

\begin{tabular}{|c|c|c|c|}
\hline Variable & $N$ & Central descriptor $N(\%)$ & Estimation \% (95\% interval limits) \\
\hline \multicolumn{4}{|l|}{ Gender } \\
\hline Male & 476 & $476(94.1 \%)$ & $94.1 \%(91.6-96.0)$ \\
\hline Female & 30 & $30(5.9 \%)$ & $5.9 \%(4.0-8.4)$ \\
\hline Age at first visit & 506 & $59.6 \pm 12.3$ & $59.6(58.5-60.7)$ \\
\hline Age at onset & 506 & $64.4 \pm 12.3$ & $64.4(63.3-65.5)$ \\
\hline Body constitution & 180 & & \\
\hline Normal weight & & $31(17.2 \%)$ & $17.2 \%(12.0-23.5)$ \\
\hline Overweight & & $58(32.2 \%)$ & $32.2 \%(25.5-39.6)$ \\
\hline Obese & & $91(50.6 \%)$ & $50.6 \%(43.0-58.1)$ \\
\hline Renal function ${ }^{a}$ & 326 & & \\
\hline Normal & & $172(52.8 \%)$ & $52.8 \%(47.2-58.3)$ \\
\hline Mild renal functional impairment & & $73(22.4 \%)$ & $22.4 \%(18.0-27.3)$ \\
\hline Moderate renal functional impairment & & $63(19.3 \%)$ & $19.3 \%(15.2-24.0)$ \\
\hline Severe renal functional impairment & & $18(5.5 \%)$ & $5.5 \%(3.3-8.6)$ \\
\hline Hyperlipidemia & 387 & & \\
\hline Not present & & $175(45.2 \%)$ & $45.2 \%(40.2-50.3)$ \\
\hline Present & & $212(54.8 \%)$ & $54.8 \%(49.7-59.8)$ \\
\hline Hypertension & 337 & & \\
\hline Not present & & $211(62.6 \%)$ & $62.6 \%(57.2-67.8)$ \\
\hline Hypertension & & $126(37.4 \%)$ & $37.4 \%(32.2-42.8)$ \\
\hline Hyperglycemia & 292 & & \\
\hline Not present & & $218(74.7 \%)$ & $74.7 \%(69.3-79.5)$ \\
\hline Present & & $74(25.3 \%)$ & $25.3 \%(20.5-30.7)$ \\
\hline Ethanol intake & 288 & & \\
\hline Not at all & & $59(20.5 \%)$ & $20.5 \%(16.0-25.6)$ \\
\hline Occasional drinker & & $90(31.3 \%)$ & $31.3 \%(25.9-36.9)$ \\
\hline Moderate drinker & & $108(37.5 \%)$ & $37.5 \%(31.9-43.4)$ \\
\hline Heavy drinker & & $31(10.8 \%)$ & $10.8 \%(7.4-14.9)$ \\
\hline Renal lithiasis history & 504 & $116(23.0 \%)$ & $23.0 \%(19.4-26.9)$ \\
\hline Concomitant drugs inducing hyperuricemia & 206 & $178(86.4 \%)$ & $86.4 \%(81.0-90.8)$ \\
\hline
\end{tabular}


Table 1 continued

\begin{tabular}{llll}
\hline Variable & $\boldsymbol{N}$ & Central descriptor $\boldsymbol{N}(\%)$ & Estimation \% (95\% interval limits) \\
\hline Joint involvement & 506 & & \\
Mono-articular (1 joint ever involved) & $153(30.2 \%)$ & $30.2 \%(26.3-34.4)$ \\
Oligo-articular (2-4 joints ever involved) & $220(43.5 \%)$ & $43.5 \%(39.1-47.9)$ \\
Poly-articular ( $>4$ joints ever involved) & $131(25.9 \%)$ & $25.9 \%(22.1-29.9)$ \\
Information on tophi (positive or negative) & 499 & & \\
Tophaceous gout & & $104(20.8 \%)$ & $20.8 \%(17.4-24.7)$ \\
$\quad$ Single tophus & $67(13.4 \%)$ & $13.4 \%(10.6-16.7)$ \\
$\quad$ Multiple tophi & $328(65.7 \%)$ & $65.7 \%(61.4-69.9)$ \\
Non-tophaceous gout & & \\
\hline
\end{tabular}

a Normal, glomerular filtration rate (GFR) $\geq 90 \mathrm{ml} / \mathrm{min}$; mild renal functional impairment, $60 \mathrm{ml} / \mathrm{min} \leq \mathrm{GFR}<90 \mathrm{ml} /$ min; moderate renal functional impairment, $30 \mathrm{ml} / \mathrm{min} \leq \mathrm{GFR}<60 \mathrm{ml} / \mathrm{min}$; severe renal functional impairment, $\mathrm{GFR} \leq 30 \mathrm{ml} / \mathrm{min}$

findings in $4(0.8 \%)$. Ultrasonography was performed in less than $5 \%$ of patients.

Samples for microscopy were mostly obtained during acute episodes of joint inflammation $(124 / 162$ or $76.5 \%)$, from nodules suspected to be tophi (28 or $17.3 \%$ ) and from previously affected but currently non-inflamed joints (12 or $2.4 \%)$.

The rate of crystal-proved diagnosis was lower in units lacking an onsite microscopy facility ( $7 \%$ vs. $34 \%, p<0.01)$ and higher in units that had a protocol for gout management (44.9\% vs. $27.6 \%, p<0.01)$ and a gout-specific clinical facility $(57.7 \%$ vs. $29.5 \%, p<0.01)$.

\section{Therapeutic Target sUA}

Twenty-seven of the rheumatology units (71\% to $87 \%$ ) anticipated that over $50 \%$ of their patients would be on target sUA. Baseline sUA was available in $449(88.7 \%)$ and $485(85.8 \%)$ of the patients at baseline and last visit, respectively. Sixty-four percent of all patients (311/ 485 ) and $66 \%$ of patients on urate-lowering medication (ULT) were at the therapeutic sUA target at their last visit (Table 2). Therefore, the expected improvement exceeded 50\% improvement in the rate of target sUA reached, as the rate of target sUA in the GEMA audit was $41 \%(286 / 701)$.

ULTs were actively prescribed in 482 (95.3\%) patients at last visit: 363 on allopurinol $(75.3 \%$ of the total with any ULT prescription), 108 $(22.4 \%)$ on febuxostat, and 11 (2.3\%) on benzbromarone. Patients who had been on ULTs at any time during follow-up included 456 (90.1\%) on allopurinol and $110(21.8 \%)$ on febuxostat. Only $11 \%$ of patients on allopurinol at their last visit had ever been prescribed other ULTs, while $93 \%$ taking febuxostat and $82 \%$ on benzbromarone had been previously prescribed allopurinol.

Allopurinol was the only ULT prescribed at a significantly lower initial dose than the final regimen (Table 3). The final dose was higher for patients with sUA within the therapeutic target range than for those who did not achieve this at their last visit. Doses of benzbromarone and febuxostat did not differ at the initial and final prescription levels, independently of whether the target sUA was reached or not.

Interestingly, of the patients who did not meet the therapeutic sUA target, 83\% lacked any mention of causal factors in their medical records, and in only $24.9 \%$ was a dose increase or switch in ULTs mentioned. Data on adherence at last visit were recorded in 372 patients: 
Table 2 Serum urate levels and rate of target serum urate levels in the whole population and by treatment subgroup analysis

\begin{tabular}{|c|c|c|c|c|c|c|}
\hline & $\begin{array}{l}\text { All patients } \\
(N=506)\end{array}$ & $\begin{array}{l}\text { On ULTs } \\
(N=482)\end{array}$ & $\begin{array}{l}\text { Not on ULTs } \\
(N=24)\end{array}$ & $\begin{array}{l}\text { Allo } \\
(N=363)\end{array}$ & $\begin{array}{l}\text { Feb } \\
(N=108)\end{array}$ & $\begin{array}{l}\mathrm{Bnz} \\
(N=11)\end{array}$ \\
\hline Baseline sUA (mg/dl) & $8.91 \pm 1.68$ & $8.94 \pm 1.67$ & $8.54^{*} \pm 1.70$ & $8.71 \pm 1.49$ & $9.66 \pm 1.90^{* *}$ & $9.40 \pm 1.95$ \\
\hline Last sUA (mg/dl) & $5.79 \pm 1.79$ & $5.73 \pm 1.76$ & $6.86^{*} \pm 1.79$ & $5.81 \pm 1.54$ & $5.52 \pm 2.37$ & $5.59 \pm 1.92$ \\
\hline $\begin{array}{l}\mathrm{UA}<6 \mathrm{mg} / \mathrm{dl} \text { at last } \\
\text { visit }(\%)\end{array}$ & $311 / 485(64.33)$ & $\begin{array}{r}302 / 457 \\
(66.08)\end{array}$ & $9 / 28^{*}(32.14)$ & $\begin{array}{c}226 / 348 \\
(64.9)\end{array}$ & $\begin{array}{r}71 / 105 \\
(67.6)\end{array}$ & $8 / 11(72.7)$ \\
\hline
\end{tabular}

$s U A$ serum uric acid, ULTs urate-lowering medications, Allo allopurinol, Feb febuxostat, Bnz benzbromarone

${ }^{*} p<0.01$ patients not on urate-lowering medications vs. patients on urate-lowering medications

${ }^{* *} p<0.01$ patients on febuxostat vs. patients on allopurinol

Table 3 Initial and last visit dose prescriptions of urate-lowering medications

\begin{tabular}{|c|c|c|c|c|c|c|}
\hline & \multicolumn{2}{|l|}{ All patients } & \multicolumn{2}{|c|}{ Last $\mathrm{sUA}<6 \mathrm{mg} / \mathrm{dl}$} & \multicolumn{2}{|c|}{ Last $\mathrm{sUA} \geq 6 \mathrm{mg} / \mathrm{dl}$} \\
\hline & $\begin{array}{l}\text { Initial dose } \\
\text { (mg/day) }\end{array}$ & $\begin{array}{l}\text { Final dose } \\
(\mathrm{mg} / \text { day })\end{array}$ & $\begin{array}{l}\text { Initial dose } \\
\text { (mg/day) }\end{array}$ & $\begin{array}{l}\text { Final dose } \\
\text { (mg/day) }\end{array}$ & $\begin{array}{l}\text { Initial dose } \\
\text { (mg/day) }\end{array}$ & $\begin{array}{l}\text { Final dose } \\
\text { (mg/day) }\end{array}$ \\
\hline Allopurinol & $136 \pm 77$ & $248 \pm 103^{*}$ & $135 \pm 76$ & $258 \pm 100$ & $141 \pm 80$ & $232 \pm 107^{* *}$ \\
\hline Benzbromarone & $61 \pm 27$ & $75 \pm 30$ & $72 \pm 23$ & $80 \pm 30$ & $33 \pm 14^{* *}$ & $63 \pm 19$ \\
\hline Febuxostat & $75 \pm 15$ & $84 \pm 23$ & $77 \pm 13$ & $83 \pm 51$ & $71 \pm 18$ & $85 \pm 20$ \\
\hline
\end{tabular}

$s U A$ uric acid

* Initial vs. final dose $p<0.05$

${ }^{* *}$ Last $\mathrm{sUA}<6 \mathrm{mg} / \mathrm{dl}$ vs. last $\mathrm{sUA} \geq 6 \mathrm{mg} / \mathrm{dl} p<0.05$

inadequate adherence was reported in 78/171 $(45.6 \%)$ of patients who failed to reach the target sUA at their last visit, and only in 52/301 $(17.3 \%)$ of those who did.

Management of hyperuricemia gout seemed to have an impact on flares, as the percentage of patients suffering a flare in the year prior to their first visit was $427(87.3 \%)$ while only 156 $(31.6 \%)$ suffered a flare in the year prior to their last visit.

\section{Other Management Variables Included in the Recommendations}

Data regarding other variables related to the evaluation and management of gout are shown in Table 4. Interestingly, obesity, lifestyle advice, and dietary recommendations were seldom noted in the clinical records, even while most patients were on an active prescription of urate-lowering medication.
Prophylaxis of flares had not been implemented in 107 (21.9\%) patients. In addition, $373(77.1 \%)$ had been prescribed colchicine, $323(86.6 \%)$ of those starting treatment during development of the flare, for a mean time period of $258 \pm 180$ days (IQR 50-595); 50 (13.4\%) patients had been on prophylactic doses above that prescribed for colchicine.

Last gout flares were treated with NSAIDs in $277 / 469$ (59.1\%) patients-at the maximally labelled dose in $61.1 \%$ of cases, with colchicine in $49(10.4 \%)$, and with corticosteroids in 143 (30.5\%) patients. Less than $2 \%$ and $1 \%$ of patients had been prescribed doses of NSAIDs or colchicine, respectively, over those labelled for acute flares. In 78 patients $(16.0 \%)$, urate-lowering medications were started, dose increased, withdrawn, or dose reduced during a flare in $57 \%, 30 \%, 9 \%$, and $4 \%$, respectively.

Comorbid conditions were, as in GEMA, most commonly evaluated when passively 
Table 4 Sensitivity analysis

\begin{tabular}{|c|c|c|c|}
\hline Recommendation & $\begin{array}{l}\text { Estimated adjustment } \\
\text { based on observations } \\
(95 \% \mathrm{CI})\end{array}$ & $\begin{array}{l}\text { Adjustment if missing values } \\
\text { DO follow recommendations } \\
(95 \% \mathrm{CI})\end{array}$ & $\begin{array}{l}\text { Adjustment if missing values DO } \\
\text { NOT follow recommendations } \\
(95 \% \mathrm{CI})\end{array}$ \\
\hline $\begin{array}{l}\text { Diagnosis based on } \\
\text { MSU observation }\end{array}$ & $32.0 \%(28.0-36.3)$ & $32.0 \%(28.0-36.3)$ & $32.0 \%(28.0-36.3)$ \\
\hline $\begin{array}{l}\text { Evaluation of } \\
\text { obesity }\end{array}$ & $36.4 \%(32.2-40.7)$ & $36.4 \%(32.2-40.7)$ & $36.4 \%(32.2-40.7)$ \\
\hline $\begin{array}{l}\text { Evaluation of renal } \\
\text { function }\end{array}$ & $65.2 \%(60.9-69.4)$ & $65.2 \%(60.9-69.4)$ & $65.2 \%(60.9-69.4)$ \\
\hline $\begin{array}{l}\text { Evaluation of lipid } \\
\text { profile }\end{array}$ & $77.6 \%(73.7-81.2)$ & $77.7 \%(73.8-81.2)$ & $77.4 \%(73.6-81.0)$ \\
\hline $\begin{array}{l}\text { Evaluation of } \\
\text { arterial pressure }\end{array}$ & $69.0 \%(64.7-73.0)$ & $69.0 \%(64.7-73.0)$ & $69.0 \%(64.7-73.0)$ \\
\hline $\begin{array}{l}\text { Evaluation of } \\
\text { hyperglycemia }\end{array}$ & $57.9 \%(53.5-62.2)$ & $57.9 \%(53.5-62.2)$ & $57.9 \%(53.5-62.2)$ \\
\hline $\begin{array}{l}\text { Evaluation of } \\
\text { alcohol intake }\end{array}$ & $57.1 \%(52.7-61.5)$ & $57.1 \%(52.7-61.5)$ & $57.1 \%(52.7-61.5)$ \\
\hline $\begin{array}{l}\text { Evaluation of renal } \\
\text { lithiasis }\end{array}$ & $23.0 \%(19.4-26.9)$ & $23.3 \%(19.7-27.2)$ & $22.9 \%(19.3-27.3)$ \\
\hline $\begin{array}{l}\text { Use of } \\
\text { hyperuricemic } \\
\text { drugs }\end{array}$ & $41.1 \%(36.8-45.5)$ & $41.1 \%(36.8-45.5)$ & $41.1 \%(36.8-45.5)$ \\
\hline $\begin{array}{l}\text { Evaluation of renal } \\
\text { excretion of sUA }\end{array}$ & $35.5 \%(31.3-39.9)$ & $36.2 \%(32.0-40.5)$ & $35.2 \%(31.0-39.5)$ \\
\hline $\begin{array}{c}\text { Global evaluation } \\
\text { of comorbidity }\end{array}$ & $87.5 \%(84.3-90.3)$ & $87.6 \%(84.3-90.3)$ & $87.4 \%(84.1-90.1)$ \\
\hline $\begin{array}{c}\text { A measure of serum } \\
\text { sUA at last visit }\end{array}$ & $95.8 \%(93.7-97.4)$ & $95.8 \%(93.7-97.4)$ & $95.8 \%(93.7-97.4)$ \\
\hline $\begin{array}{c}\text { Evaluation of flares } \\
\text { at the last year }\end{array}$ & $90.7 \%(87.8-93.1)$ & $90.7 \%(87.8-93.1)$ & $90.7 \%(87.8-93.1)$ \\
\hline $\begin{array}{l}\text { Global evaluation } \\
\text { of follow-up }\end{array}$ & $97.4 \%(95.6-98.6)$ & $97.4 \%(95.6-98.6)$ & $97.4 \%(95.6-98.6)$ \\
\hline Overweight control & $31.2 \%(27.2-35.5)$ & $31.2 \%(27.2-35.5)$ & $31.2 \%(27.2-35.5)$ \\
\hline $\begin{array}{l}\text { Alcohol intake } \\
\text { restriction }\end{array}$ & $56.4 \%(52.0-60.8)$ & $56.5 \%(52.1-60.9)$ & $56.3 \%(51.9-60.7)$ \\
\hline $\begin{array}{l}\text { Global } \\
\text { recommendation } \\
\text { on lifestyle }\end{array}$ & $31.2 \%(27.2-98.6)$ & $31.2 \%(27.2-98.6)$ & $31.2 \%(27.2-98.6)$ \\
\hline
\end{tabular}


Table 4 continued

\begin{tabular}{llll}
\hline Recommendation & $\begin{array}{l}\text { Estimated adjustment } \\
\text { based on observations } \\
(\mathbf{9 5 \%} \mathbf{~ C I})\end{array}$ & $\begin{array}{l}\text { Adjustment if missing values } \\
\text { DO follow recommendations } \\
(\mathbf{9 5 \%} \mathbf{~ C I})\end{array}$ & $\begin{array}{l}\text { Adjustment if missing values DO } \\
\text { NOT follow recommendations } \\
(\mathbf{9 5 \%} \mathbf{C I})\end{array}$ \\
\hline $\begin{array}{l}\text { Management of } \\
\text { acute flares }\end{array}$ & $100 \%$ & $100 \%$ & $100 \%$ \\
$\begin{array}{c}\text { Overall } \\
\text { management of } \\
\text { hyperuricemia }\end{array}$ & $41.1 \%(36.8-45.5)$ & $41.1 \%(36.8-45.5)$ & $41.1 \%(36.8-45.5)$ \\
$\begin{array}{c}\text { Treatment with } \\
\text { allopurinol }\end{array}$ & $90.1 \%(87.2-92.6)$ & $90.1 \%(87.2-92.6)$ & $90.1 \%(87.2-92.6)$ \\
\hline
\end{tabular}

$M S U$ monosodium urate, $s U A$ uric acid

retrievable from analysis (glucose, lipids, creatinine) or when a previous diagnosis or treatment was recorded in the clinical file (hyperlipidemia, diabetes, hypertension) rather than from active searches such as arterial pressure, height, or weight measurements. Indeed, data to evaluate obesity were retrieved in only one-third of patients.

\section{DISCUSSION}

Surveys are commonly used to evaluate the state of art, but may not accurately reflect real clinical practice as they are greatly subject to bias. In this audit, we retrieved the anticipated/surveyed/perception of investigators on what the final rates of gold-standard diagnosis (GSD) and achievement of the targeted therapeutic sUA would be, and they were not in accordance with final results, suggesting that surveys are not reliable compared to audits.

Audits more accurately reflect real practice, despite all the limitations regarding the retrospective nature of the design. Management of gout may differ widely from average [2] to outstanding specialized practices [4]. It is far from the authors' intention to cast blame or praise any particular setting, but rather to suggest that if a particular specialist's practice is suboptimal, this can result in errors used by general practitioners for their own benchmarking purposes. We cannot ask of our colleagues a performance standard that not even specialists can currently seem to attain.

The GEMA study was designed to evaluate the state of gout management as practiced by hospital-based rheumatologists prior to the implementation of the 2006 EULAR recommendations. We found low rates of both GSD and achievement of target sUA level [5]. GEMA2 was carried out to evaluate whether there was a significant improvement in the management of gout after the 2006 EULAR recommendations but before the 2012 ACR guidelines and 2013 national guidelines would have had any impact on rheumatologic approaches to gout management. Although we cannot infer causality, it is reasonable to suggest that heightening awareness of the disease, via the dissemination of recommendations, is highly advisable.

This retrospective audit shows an improvement in both crystal-based GSD and a targeted sUA approach to treatment (below $6 \mathrm{mg} / \mathrm{dl}$ or $0.36 \mathrm{mmol} / \mathrm{l})$, the latter with an improvement of more than $50 \%$ above that observed in the previous GEMA, an advance achieved at the last visit in approximately two-thirds of the patients. Difficult-to-control patients are more commonly under the charge of specialists, and exhibit higher rates of comorbidities and medication prescription [10]. Thus, the overall population examined herein represents a difficult-to-treat, not-best-case scenario, albeit notworst-case clinical scenario, thus reinforcing the value of these findings. 
The rate of GSD from GEMA to GEMA-2 improved, but did not reach 50\% improvement. As in GEMA, most of the cases with GSD stemmed from flares, where infection is a possibility and synovial fluid is far more accessible than during inter-critical periods. We explored whether this could be due to the use of ultrasound (US) as a diagnostic tool, only to find out that it was only performed in a small number of patients, contributing to diagnosis in less than $1 \%$ of them. This may change in the near future, as US has been shown to be quite accurate for diagnosis in patients with crystal-proven gout [11]. Although having an on-site microscopy facility was not associated with a good rate of GSD, not having one was associated with less than 10\% GSD.

We were able to ascertain that a significant ( $\geq 50 \%$ ) improvement from the previous audit was achieved in the percentage of patients reaching the sUA target of below $6 \mathrm{mg} / \mathrm{dl}$. Despite this improvement, the final dose of allopurinol was not greater than that recorded in GEMA. Dissemination of the EULAR recommendations at a given treatment facility was associated with better ratios of target sUA, suggesting that increased awareness of gout management had an impact on clinical practice. The availability of febuxostat may have also contributed to the improved rate of target sUA compared to GEMA. In fact, febuxostat was not available, but was mainly used as a second-line treatment for patients with higher baseline sUA, who are less likely to reach sUA on average doses of allopurinol [12].

Clinical inertia looks like a plausible limitation to achieving the sUA target [13], as no active measure was reportedly implemented (increase in dose, switch, or combination) in most of those patients who failed to reach sUA, although a given clinician's perception of inadequate adherence to treatment may have also been a variable.

Doses of febuxostat seldom exceeded $80 \mathrm{mg} /$ day; in fact, it only did so for those patients who failed to reach the $6 \mathrm{mg} / \mathrm{dl} \mathrm{sUA}$ target while on $80 \mathrm{mg} /$ day. Benzbromarone was infrequently prescribed and mostly at low doses and in combination with allopurinol. At average doses, its use was only about one-fourth of the maximum $200 \mathrm{mg}$ a day recommended dose. Interventions to avoid clinical inertia such as the use of electronic templates have been shown to be useful [14].

Most patients were prescribed prophylaxis, principally with colchicine at adequate doses. Interestingly, prophylaxis with colchicine was mostly started during a flare. Nonetheless, colchicine was not the preferred medication for flares, with corticosteroids being prescribed at a three-fold higher rate. These treatment choices may reflect the presence of underlying comorbidities.

Despite this, in one in six patients, changes in ULT were made during an ongoing flare, contrary to national standards, in which this practice is specifically discouraged.

The main strength of this study is that it is an audit of clinical rheumatology practice under best practice conditions. Audits, as shown also in the "Results" section, lack the bias of personal perceptions inherent to surveys. In addition, the principal co-variables were retrieved from the majority of files. The main limitations include the retrospective capturing of data, and the impossibility to form any conclusions regarding causality based on the observed associations.

\section{CONCLUSIONS}

The diagnosis of gout has improved in clinical rheumatology, although not as much as expected. In addition, ultrasonography as a diagnostic tool has not yet been implemented despite the fact that adequate equipment was available in most offices. Achievement of target sUA at last visit has increased more than $50 \%$ since the previous audit, with two-thirds of patients reaching this benchmark. However, clinical inertia-e.g., increasing doses or switching medications-should be avoided, as should poor adherence, two issues that should be taken into account for making further advancements in this area. 


\section{ACKNOWLEDGEMENTS}

Funding. This work was partially supported by Fundación Española de Reumatología with an unrestricted grant from Menarini España, including funding for article Open Access processing charges.

Authorship. All named authors meet the International Committee of Medical Journal Editors (ICMJE) criteria for authorship for this manuscript.

Medical Writing, Editorial, and Other Assistance. The authors are grateful to those who have actively contributed to the GEMA-2 but do not fulfill criteria for authorship: Ms. Sabina Perez, Ms. Milena Gobbo, Prof. Federico Diaz-González, Dr. Estibaliz Loza, and all investigators who contributed to data collection. All authors designed the study, JC Sanchez-Piedra, JT Sanchez-Costa, and F Perez-Ruiz performed statistical analyses and wrote the draft manuscript without any external support. All other authors actively discussed results, significantly contributed to the manuscript, and approved the final version.

Disclosures. C Moragues: Grant/research support from Pfizer; honorarium as speaker from Menarini, Novartis, Amgen, and Bioventus. F Sivera: grant/research support from AbbVie; consultant fees from Pfizer; honorarium as speaker Menarini. E. De Miguel: Grant/research support from AbbVie and Pfizer, honorarium as speaker from Abbvie, MSD, and Novartis and consultant fees from Abbvie and Novartis. JT Sanchez-Costa: employee, Investigation Unit, Spanish Foundation for Rheumatology. JC Sanchez: employee, Investigation Unit, Spanish Foundation for Rheumatology. M Andrés: consulting fees from Grünenthal. F Perez Ruiz: consulting/speaker/educative programs fees from Algorithm, Amgen, Astellas, Ardea, AstraZeneca, Cimabay, Grünenthal, Menarini. C. Diaz-Torne: fees from Menarini \& Grúnenthal. M Jimenez-Palop: nothing to disclose.
Compliance with Ethics Guidelines. The study was centrally approved by the Ethics and Investigation Board (EIB) of the Basque Country and subsequently by every EIB of the centers involved. This study did not include any new intervention.

Open Access. This article is distributed under the terms of the Creative Commons Attribution-NonCommercial 4.0 International License (http://creativecommons.org/licenses/ by-nc/4.0/), which permits any noncommercial use, distribution, and reproduction in any medium, provided you give appropriate credit to the original author(s) and the source, provide a link to the Creative Commons license, and indicate if changes were made.

\section{REFERENCES}

1. Doherty M, Jansen TL, Nuki G, et al. Gout: why is this curable disease so seldom cured? Ann Rheum Dis. 2012;71(11):1765-70.

2. Cottrell E, Crabtree V, Edwards JJ, Roddy E. Improvement in the management of gout is vital and overdue: an audit from a UK primary care medical practice. BMC Fam Pract. 2013;14:170.

3. Reaves E, Arroll B. Management of gout in a South Auckland general practice. J Prim Health Care. 2014;6(1):73-8.

4. Conway R, Coughlan RJ, Carey JJ. Adherence to uric acid treatment guidelines in a rheumatology clinic. Clin Rheumatol. 2012;31(12):1707-11.

5. Perez-Ruiz F, Carmona L, Yebenes MJ, et al. An audit of the variability of diagnosis and management of gout in the rheumatology setting: the Gout Evaluation and Management Study. J Clin Rheumatol. 2011;17(7):349-55.

6. Zhang W, Doherty M, Pascual E, et al. EULAR evidence based recommendations for gout Part II. Management. Report of a Task Force of the EULAR Standing Committee for International Clinical Studies Including Therapeutics (ESCISIT). Ann Rheum Dis. 2006;65(5):1312-24.

7. Zhang W, Doherty M, Pascual E, et al. EULAR evidence based recommendations for gout Part I. Diagnosis. Report of a Task Force of the EULAR Standing Committee for international clinical 
studies including therapeutics (ESCISIT). Ann Rheum Dis. 2006;65:1301-11.

8. Khanna D, Fitzgerald JD, Khanna PP, et al. 2012 American College of Rheumatology guidelines for management of gout. Part 1: systematic nonpharmacologic and pharmacologic therapeutic approaches to hyperuricemia. Arthritis Care Res (Hoboken). 2012;64(10):1431-46.

9. Sociedad Española de Reumatología. Clinical Management Guidelines for Gout. Sociedad Española de Reumatología. 2015. http://www.ser.es/wpcontent/uploads/2015/09/GuipClinGot_1140226_ EN.pdf. Accessed 27 Nov 2017.

10. Khanna P, Khanna D, Storgard C, Baumgartner S, Morlock R. A world of hurt: failure to achieve treatment goals in patients with gout requires a paradigm shift. Postgrad Med. 2016;128(1):34-40.

11. Ogdie A, Taylor WJ, Neogi T, et al. Performance of ultrasound in the diagnosis of gout in a multi- center study: comparison with monosodium urate crystal analysis as the gold standard. Arthritis Rheumatol. 2016;69(2):429-38.

12. Becker MA, Schumacher HR Jr, Wortmann RL, et al. Febuxostat compared with allopurinol in patients with hyperuricemia and gout. $\mathrm{N}$ Engl $\mathrm{J}$ Med. 2005;353(23):2450-61.

13. Maravic M, Hincapie N, Pilet S, Flipo RM, Liote F. Persistent clinical inertia in gout in 2014: an observational French longitudinal patient database study. Jt Bone Spine. 2017. doi:https://doi.org/10. 1016/j.jbspin.2017.03.013.

14. Moffat $\mathrm{K}, \mathrm{McNab} \mathrm{D}$. Improving management of gout in primary care using a customised electronic records template. BMJ Qual Improv Rep. 2015;4(1). doi:https://doi.org/10.1136/bmjquality.u204832. w2038. 